\title{
ALFABETIZAÇÃO CIENTÍFICA USANDO O TEMA DOS QUELÔNIOS AMAZÔNICOS
}

\section{SCIENTIFIC LITERACY USING AMAZONIAN TURTLES THEME}

\author{
Sabrina Barroso Menezes ${ }^{1}$ \\ Augusto Fachín Terán ${ }^{2}$ \\ Richard Carl Vogt ${ }^{3}$
}

\begin{abstract}
Resumo: O objetivo deste trabalho foi analisar de que forma o conhecimento adquirido sobre os quelônios amazônicos contribuiu para o processo de Alfabetização Cientifica em estudantes do $7^{\circ}$ ano do Ensino Fundamental II. A pesquisa do tipo qualitativa foi realizada no Bosque da Ciência do Instituto Nacional de Pesquisas da Amazônia. Foram aplicados questionários em quatro turmas de escolas públicas e privadas de Manaus. Os estudantes incorporaram conceitos científicos sobre a diversidade de espécies, diferenças morfológicas e dimorfismo sexual. Partindo do pressuposto de que só ocorre mudança diante do conhecimento, destacamos a influência do trabalho realizado não só na formação de estudantes cientificamente alfabetizados, mas também na preparação de cidadãos preocupados com o meio ambiente.
\end{abstract}

Palavras-chave: Alfabetização Científica; Educação Não Formal; Quelônios amazônicos.

\begin{abstract}
The objective of this work was to analyze the how acquired understandings about Amazonian turtles contribute to the process of Scientific Literacy in $7^{\text {th }}$ grade students attending Elementary school. This a qualitative research conducted at the Science Forest at National Institute of Amazonian Research. For data gathering we applied questionnaires in four different classes of both private and public schools, in Manaus. The students acquired scientific concepts about species diversity, morphological differences, and sexual dimorphism. From the presumption that changes only occur from obtaining knowledge, we emphasize the influence of this study made not only in the formation of science literate students, but also in the preparation of citizens concerned with the environment.
\end{abstract}

Keywords: Scientific Literacy; Non-Formal Education; Amazonian turtles.

\section{Introdução}

A educação prepara o ser humano para o desenvolvimento de suas atividades no percurso de sua existência. Nesse sentido, faz-se necessário uma educação, ao longo da vida, a fim de dar suporte a vários aspectos, sejam eles, econômicos, sociais, científicos e tecnológicos, impostos por um mundo globalizado (CASCAIS; FACHÍN-TERÁN, 2014).

\footnotetext{
${ }^{1}$ Bolsista do PIBIC/INPA/CNPq/FAPEAM. Centro de Estudos de Quelônios da Amazônia CEQUA/INPA. Manaus, Amazonas, Brasil. E-mail: sabrinabarrosomenezes@live.com

${ }^{2}$ Doutorado em Biologia pelo Instituto Nacional de Pesquisas da Amazônia (INPA). Universidade do Estado do Amazonas (UEA), Manaus, Amazonas, Brasil. E-mail: fachinteran@ yahoo.com.br

${ }^{3}$ Pós Doutor em Divisão de Anfíbios e Répteis do Carnegie Museum of Natural History em Pittsburgh, Pennsylvania, EUA. Coordenação de Pesquisas em Biologia Aquática, Instituto Nacional de Pesquisas da Amazônia, Manaus, Amazonas, Brasil. E-mail: dickturtlevogt@gmail.com
} 
A educação pode ser do tipo formal, que se dá por meio de instituições, com regras, seguindo leis e normas (CASCAIS; FACHÍN-TERÁN, 2014); informal, que é descrita como aquela que ocorre "durante o seu processo de socialização gerada nas relações e relacionamentos intra e extra familiares" (GOHN, 2006, p.28), sendo então relações que ocorrem com os membros da família, amigos, vizinhos; e a não formal, que segundo Gohn (2006) é aquela que ocorre com o compartilhamento de experiências, onde existe atividades coletivas.

Jacobucci (2008) diferencia os espaços educativos "não formais" em institucionalizados (museus, zoológicos, planetários, entre outros) e não institucionalizados (rios, praias, lagos, florestas, ruas, entre outros). É importante destacar a utilização de outros espaços para a complementação dos conteúdos abordados em sala de aula, visto que "a grande quantidade de informações que surge no mundo moderno nos faz perceber que a escola, por si só, não consegue dar conta ou resolver todos os problemas oriundos do conhecimento" (MACIEL; FACHÍN-TERÁN, 2014, p.23).

Diante disso percebe-se a necessidade de estabelecer parcerias e utilizar outros espaços educativos presentes na comunidade, para que os estudantes tenham uma educação mais contextualizada (CASCAIS; FACHÍN-TERÁN, 2014). É necessário que as escolas integrem visitas aos Espaços Não Formais com objetivo de ensino de temas científicos, e não somente como passeio ou atividade complementar, sendo essa interação parte do processo do ensino e da aprendizagem (CASCAIS; FACHÍN-TERÁN, 2015). Nesse sentido, os Espaços Não Formais se tornam fundamentais no processo de ensinoaprendizagem dos alunos, visto que as aulas ministradas nesses espaços favorecem a observação e a problematização dos fenômenos físicos e biológicos de uma forma mais concreta (CUNHA, 2009).

A Alfabetização Científica (AC) é um meio utilizado para que os indivíduos sejam alfabetizados para ler a linguagem das ciências, tendo aporte para compreender as questões que ocorrem em sua volta, ajustando-as para a melhoria de sua realidade (CHASSOT, 2010). Para Lorenzetti e Delizoicov (2001) a AC proporciona aos indivíduos uma melhor visão sobre o mundo, devido a isto, seria de total relevância que os indivíduos sejam AC desde a primeira idade escolar.

Os Quelônios amazônicos são importantes devido à função ecológica que estes repteis tem para o ecossistema amazônico. Segundo Andrade (2007) à caça e comercialização de adultos e a coleta de seus ovos vem sistematicamente afetando as 
populações destes repteis. Eis aí a importância de trabalhar a AC para a preservação e conservação dos quelônios amazônicos.

Nesta pesquisa trabalhamos a $\mathrm{AC}$ com os seguintes objetivos: 1) Descrever os espaços do Bosque da Ciência que podem ser usados no processo de AC, usando o tema dos quelônios Amazônicos; 2) Analisar de que forma o conhecimento adquirido contribuiu para o processo de AC.

\section{Procedimentos Metodológicos}

O percurso metodológico está ancorado na abordagem qualitativa e na utilização das técnicas de observação participante e aplicação de questionário com perguntas abertas. Erickson (1986) usa o termo interpretativo para este tipo de pesquisa por que é mais inclusivo e não dá à pesquisa a conotação de ser essencialmente não quantitativa. Nesta abordagem o interesse central da pesquisa na questão é a questão dos significados que as pessoas atribuem a eventos e objetivos, em suas ações e interações dentro de um contexto social e na elucidação e exposição desses significados pelo pesquisador (MOREIRA, 2011). Contudo, também foram considerados dados quantitativos para análise interpretativa, principalmente referente ao questionário aplicado aos estudantes.

As respostas foram analisadas mediantes a comparação dos conceitos padrões para as temáticas abordadas, descritos no apêndice 1, sendo aceita a resposta como satisfatória quando foi citado pelo menos duas das características dos conceitos padrões.

A pesquisa foi realizada no Bosque da Ciência, localizado no Instituto Nacional de Pesquisas da Amazônia (INPA), e em três escolas públicas e uma escola privada da cidade de Manaus. Os sujeitos foram 100 alunos, 77 das escolas públicas e 23 da privada, do $7^{\circ}$ ano de Ensino Fundamental II.

Para indagar o conhecimento prévio dos estudantes sobre os quelônios Amazônicos, foi aplicado um questionário nas salas de aula das escolas. A verificação dos saberes foi realizada após visita ao Bosque da Ciência com o mesmo instrumento.

O tempo médio usado durante as visitas ao Bosque da Ciência foi de $1 \mathrm{~h}$ e $30 \mathrm{~min}$ a $2 \mathrm{~h}$ de duração, tempo suficiente para os estudantes percorrerem os espaços selecionados. Neste período foram visitados ambientes com presença dos quelônios, nos agrupamentos que a continuação apresentamos:

Casa da Ciência + Ilha da Tanimbuca: onde foi trabalhado o contexto histórico dos ribeirinhos e as tradições do consumo de carne dos quelônios na região Amazônica. Foi 
realizada uma explicação sobre os táxons, diversidade de espécies, morfologia, alimentação, habitat, modo de reprodução e importância ecológica dos quelônios.

Ilha da Tanimbuca + Recanto dos Inajás: onde foi trabalhada a diversidade de espécies contidas nesses espaços, características morfológicas, diferenciação entre espécies, habitat, alimentação, reprodução e interação com outras espécies de peixes, além de ressaltar a sua importância ecológica.

Lago Amazônico + Centro de Estudos dos Quelônios da Amazônia (CEQUA): onde foi trabalhada a diversidade de espécies, características morfológicas, diferencias entre as espécies, habitat, alimentação, interação com outras espécies, reprodução, dimorfismo sexual e sua importância ecológica.

\section{Resultados e Discussão}

O espaço não formal institucionalizado chamado de Bosque da Ciência tem uma área de aproximadamente 13 hectares, e esta localizada no perímetro urbano da cidade de Manaus na Zona Central - Leste. Foi projetado e estruturado para fomentar e promover o desenvolvimento do programa de Difusão Científica e Educação Ambiental do INPA, e preservar os aspectos da biodiversidade existente no local. O local já foi descrito por Rocha e Fachín-Terán (2010) e Maciel e Fachín-Terán (2014). Este ambiente que tem uma serie de atrativos, apresenta quatro espaços com presença dos quelônios que a continuação apresentamos:

Casa da Ciência: inaugurada em 20 de maio de 1993, dois anos antes de se iniciarem as atividades no BC. É um espaço que permite uma visão de forma interativa, transmite aos visitantes os projetos e programas realizados pelo INPA, e como os resultados dessas pesquisas podem interferir diretamente no dia a dia das pessoas. É um local que mostra a Amazônia de maneira histórica podendo transmitir atividades costumeiras de ribeirinhos e as fases pelas que a região passou (fig. 1). 

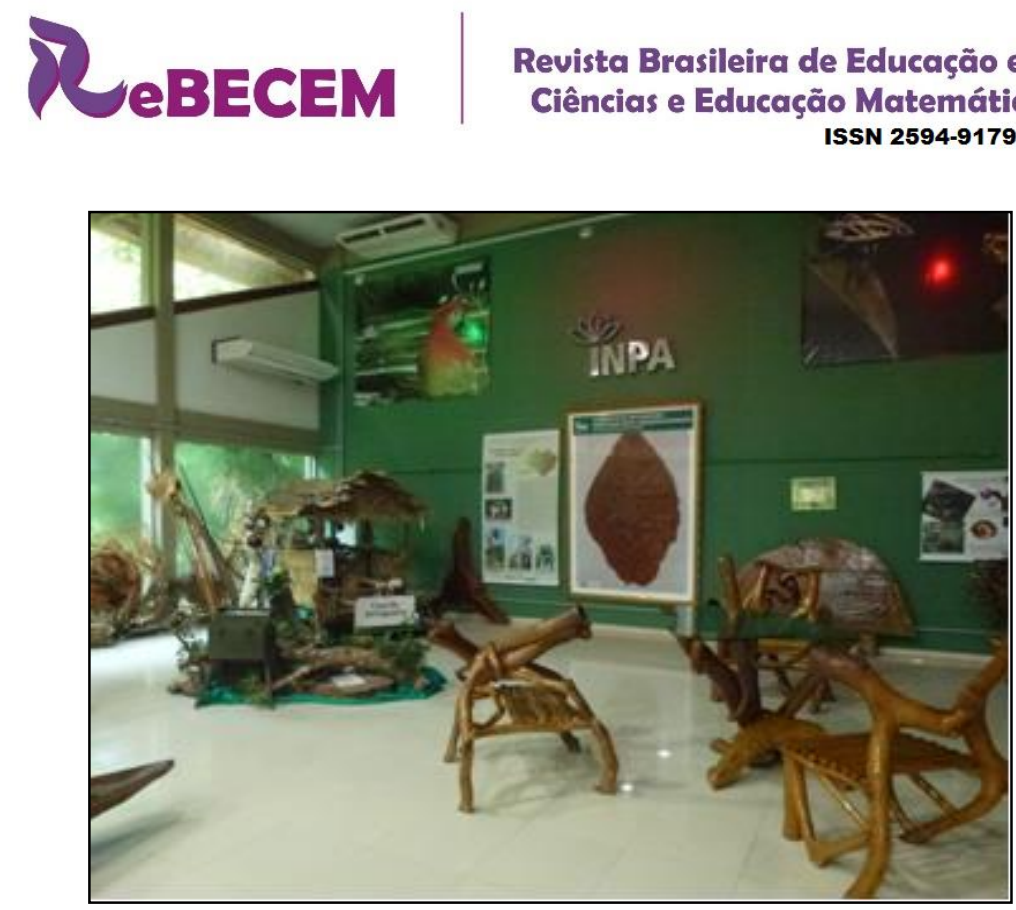

Figura 1: Interior da casa da ciência

Fonte: Figura selecionada pelos pesquisadores a partir da coleta de dados.

É composto por painéis informativos, animais empalhados, incluindo tartarugas da Amazônia, com informações impressas interagindo com material da fauna e da flora amazônicas, maquetes, aquários, amostras de produtos tecnológicos, implantação de um ambiente interativo com conteúdos digitais diversificados, uso de tecnologia de comunicação e informática e recursos multimídia, além de exposições digitalizadas.

A Ilha Tanimbuca: retrata a conservação ambiental e seus componentes harmoniosos, onde compreende uma calha e espelho d'água que compõem vários peixes e quelônios da região (fig. 2). Tem uma arvore emergente de mais de 600 anos chamado de Tanimbuca (Buchenavea huberii - Combretaceae), que retrata sua existência o tempo em que o Brasil foi descoberto.

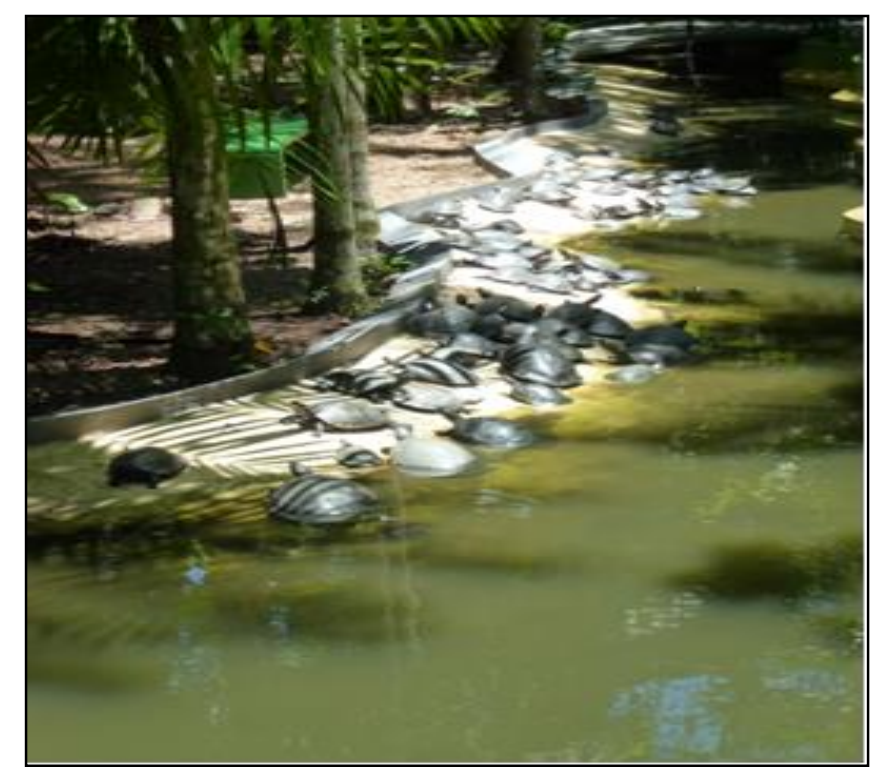

Figura 2: Ilha da Tanimbuca com os quelônios

Fonte: Figura selecionada pelos pesquisadores a partir da coleta de dados. 
O recanto dos inajás: ambiente composto por vegetação de palmeiras conhecidas como “inajás” (Maximiliana maripa). Possui um lago artificial com diversas espécies de peixes, entre eles o tambaqui, os acaras e poraquês, plantas aquáticas e tartarugas como o tracaja, $P$. unifilis e a irapuca, $P$. erythrocephala (fig. 3 ).

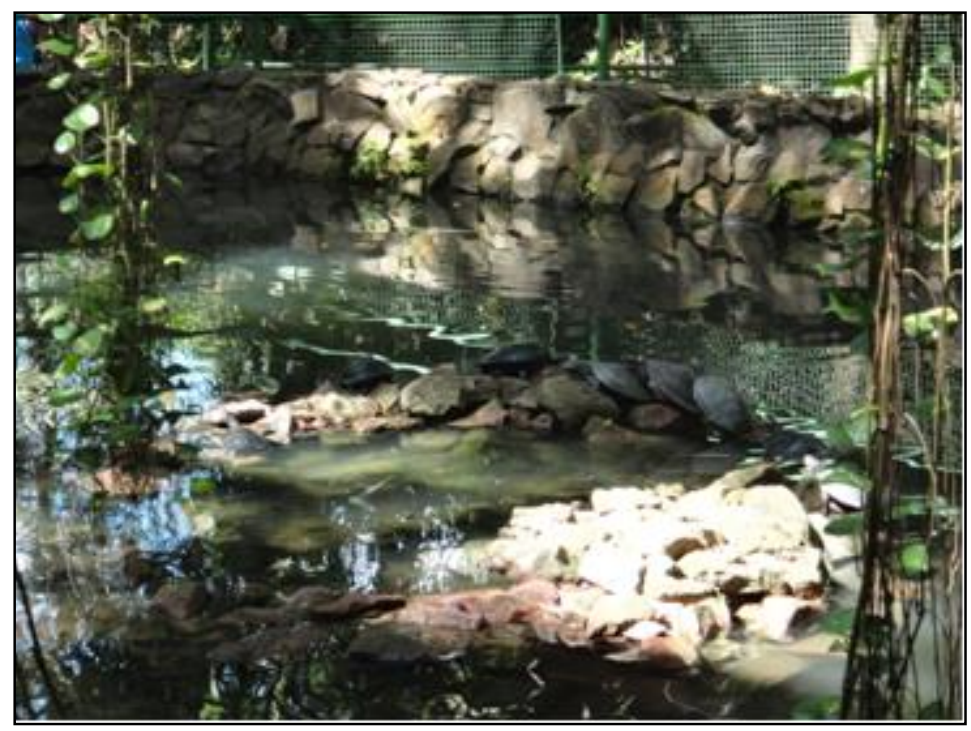

Figura 3: Recanto dos Inajás.

Fonte: Figura selecionada pelos pesquisadores a partir da coleta de dados.

O Lago Amazônico: é um ambiente artificial que retrata os lagos da região. É habitado por diversas espécies de quelônios, como a Tartaruga-da-Amazônia (Podocnemis expansa), Tracajas (P. unifilis), Irapuca (P. erythrocephala) e peixes como o tambaqui (Colossoma macropomum), tucunaré (Cichla ocellaris) e pirarucu (Arapaima gigas) (fig. 4).

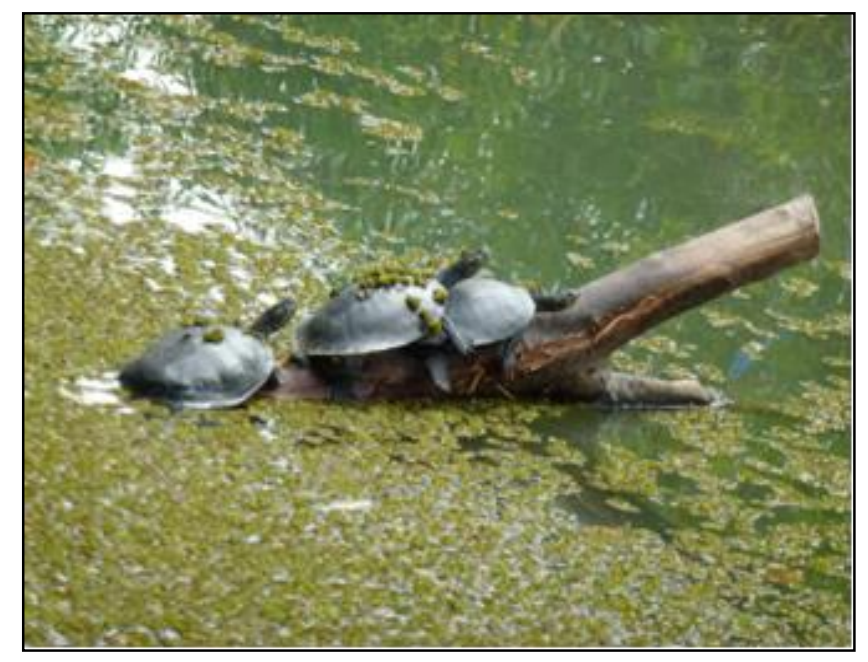

Figura 4: Quelônios no Lago Amazônico

Fonte: Figura selecionada pelos pesquisadores a partir da coleta de dados. 
Centro de Estudos dos Quelônios da Amazônia (CEQUA): O INPA com o intuito de desenvolver pesquisas e educação ambiental sobre a conservação de quelônios inaugurou no dia 12 de fevereiro de 2015 nas dependências do Bosque da Ciência, o CEQUA. Este é o primeiro centro do mundo habilitado para estudos e exibição de quelônios amazônicos (fig. 5).

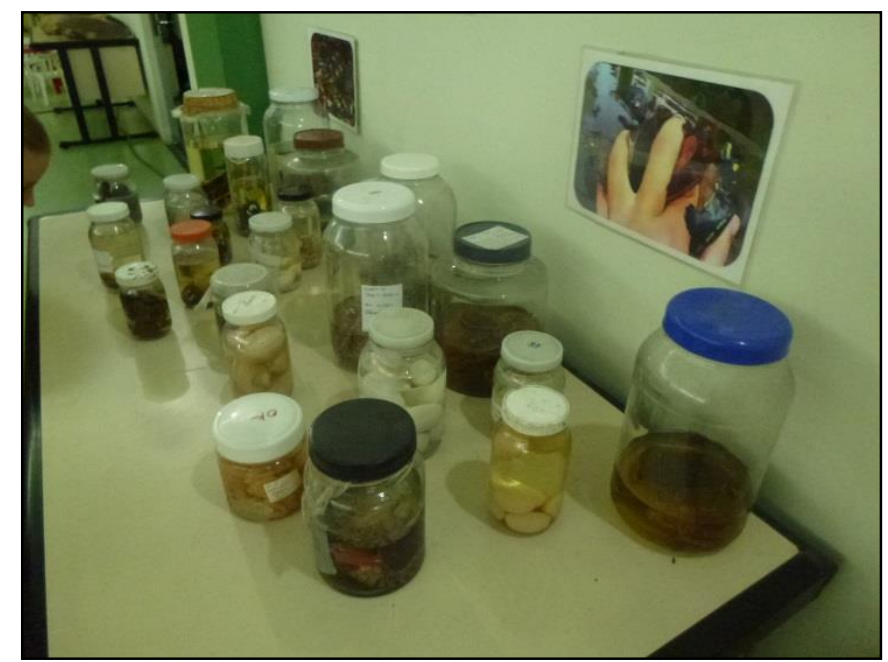

Figura 5: Amostras de material biológico no CEQUA

Fonte: Figura selecionada pelos pesquisadores a partir da coleta de dados.

\subsection{Conhecimentos prévios dos estudantes sobre os quelônios amazônicos}

O levantamento sobre os conhecimentos prévios dos estudantes aconteceu na escola. Sobre os temas abordados nos questionários foram listados os conceitos padrões com base em pesquisa já realizadas por Vogt (2008), no Livro Tartarugas da Amazônia.

Dos 100 alunos, 85 manifestaram que sabiam sobre tartarugas e 15 desconheciam sobre esse assunto. Percebemos que apesar de o nome "tartaruga" ser conhecido, ainda há estudantes que não conhecem estes animais.

Na Amazônia existem 18 espécies de quelônios, nesta pesquisa abordaremos o conhecimento de 14 delas.

\subsection{Conhecimento dos estudantes sobre as diferentes temáticas abordadas}

Quando comparados as respostas pré e pós aplicação dos questionários, verificamos que houve um aumento significativo em todas as respostas sobre as temáticas pesquisadas. Houve uma maior compreensão dos temas dimorfismo sexual e alimentação dos quelônios. O que significa que há indícios de alfabetização cientifica (Tabela 1). 
Tabela 1: Respostas dos estudantes Pré e Pós-aplicação do questionário sobre as diferentes temáticas abordadas

\begin{tabular}{l|c|c|c|c}
\hline \multirow{2}{*}{ TEMÁTICAS } & \multicolumn{3}{|c}{ ENTREVISTA (N=100) } \\
\cline { 2 - 5 } & \multicolumn{2}{|c}{ PRÉ } & \multicolumn{2}{c}{ PÓS } \\
\cline { 2 - 5 } & RS & RNS & RS & RNS \\
\hline Morfológicas & 58 & 42 & 89 & 11 \\
\hline Habitat & 50 & 50 & 75 & 25 \\
\hline Alimentação & 31 & 69 & 62 & 38 \\
\hline Reprodução & 23 & 77 & 46 & 54 \\
\hline Dimorfismo sexual & 10 & 90 & 54 & 46 \\
\hline
\end{tabular}

$\mathrm{RS}=$ Respostas satisfatórias, RNS = Não satisfatórias

Fonte: Dos autores.

Nas respostas dadas pelos estudantes (Quadro 1), é notório o conhecimento científico de alguns estudantes, como por exemplo E6, que ao se referir ao casco chamálo por carapaça, mostrando também que existem diferentes espécies, se referindo a diversidade. O E56 já se refere à Classe dos répteis. O E82 já é mais específico, citando a existência das 17 espécies de quelônios amazônicos, além de categorizá-los como quelônios (ordem das tartarugas). Já o E90 cita a classe (répteis) e a ordem (quelônios), também que elas utilizam o casco para se defender e se refere a parte ventral do animal como "plasto", referente ao plastrão, que é a parte ventral destes animais.

\begin{tabular}{|c|c|c|}
\hline Estudantes & \multicolumn{2}{|c|}{ O que são tartarugas? Você já viu uma? Fale como elas são. } \\
\hline & Pré & Pós \\
\hline E6 & $\begin{array}{l}\text { Eu acho que elas são } \\
\text { mamíferos. Não. }\end{array}$ & $\begin{array}{l}\text { Sim, ela era bem grande e sua carapaça também. } \\
\text { Existe vários tipos de tartarugas, algumas grandes e } \\
\text { outras pequenas. }\end{array}$ \\
\hline E56 & $\begin{array}{l}\text { Eu já vi na } T V . \text { Elas eram do } \\
\text { tipo que vivem na água. Elas } \\
\text { tem casca grande e anda } \\
\text { lentamente. }\end{array}$ & $\begin{array}{l}\text { São repteis, Com casco grande e duro. Conheci vários } \\
\text { tipos de tartarugas. }\end{array}$ \\
\hline E82 & $\begin{array}{l}\text { São repteis. Sim, possuem } \\
\text { uma pele enrrugada, um } \\
\text { casco duro, são repteis que } \\
\text { botam ovos. }\end{array}$ & $\begin{array}{l}\text { Na Amazônia existem } 17 \text { espécies com suas } \\
\text { características. São répteis, que são chamadas de } \\
\text { quelônios. Vi no Inpa e antes. Existem várias espécies, } \\
\text { uma com manchas amarelas na cabeça, outras } \\
\text { vermelhas, pequenas e grandes, etc. }\end{array}$ \\
\hline E90 & $\begin{array}{l}\text { Sim, é um animal. Tinha uma } \\
\text { casca para se proteger. São } \\
\text { vegetarianas. }\end{array}$ & $\begin{array}{l}\text { São quelônios, répteis. Vi adultas, jovens e filhote e } \\
\text { tinha uma carapaça e também o plasto. Em cima dela } \\
\text { tinha um casco uma proteção chamada carapaça. }\end{array}$ \\
\hline
\end{tabular}

Quadro 1: Respostas dos estudantes Pré e Pós-aplicação do questionário sobre a morfologia dos Quelônios.

Fonte: Dos autores.

Sobre o habitat dos quelônios, somente 50 dos estudantes conseguiram responder antes da visita. Após a vista, 75 deram uma resposta satisfatória (Quadro 2).

Na pré-aplicação do questionário predomina o conhecimento de que estes animais vivem em meio aquático, já após a visita ao Bosque da Ciência, constatamos que os 
estudantes possuem uma visão mais ampla, reconhecendo que existem espécies tanto aquáticas quanto terrestres, e que vivem em diversos ambientes, como os rios, mar (se referindo a tartarugas marinhas), lagos e igarapés. Mostra-se então a assimilação do conhecimento por parte destes estudantes (Quadro 2).

\begin{tabular}{|l|l|l|}
\hline \multicolumn{1}{|c|}{ Aluno } & \multicolumn{2}{|l|}{ Onde as tartarugas vivem? } \\
\hline & Pré & Pós \\
\hline E17 & Nas águas & Depende, umas vivem na terra e outras na água. \\
\hline E51 & Em lagoas & Em rio, mar ou lagos. \\
\hline E69 & Não sei & Tanto na terra quanto no água \\
\hline E86 & Na água e na terra & Nos rios, lagos e igarapés. \\
\hline
\end{tabular}

Quadro 2: Respostas dos estudantes Pré e Pós-aplicação do questionário sobre o habitat dos Quelônios.

Fonte: Dos autores.

Sobre o tema da alimentação dos quelônios, o conhecimento dos estudantes mudou $100 \%$ com respeito ao conhecimento prévio. Sendo que um estudante (E90) conseguiu caracterizar e diferenciar os carnívoros dos herbívoros (Quadro 3).

\begin{tabular}{|l|l|l|}
\hline Estudantes & \multicolumn{2}{|l|}{ Do que elas se alimentam? } \\
\hline & Pré & Pós \\
\hline E22 & $\begin{array}{l}\text { Elas se alimentam de } \\
\text { plantas }\end{array}$ & Algumas de peixes e outras de plantas. \\
\hline E53 & De algas & Algumas se alimentam de peixes outras de semente \\
\hline E82 & Não sei & Se alimentam de peixe e algumas de plantas \\
\hline E90 & De algas e plantas & $\begin{array}{l}\text { Carnívoro: de peixes e restos de carne } \\
\text { Herbívoro: plantas e pequenas frutas }\end{array}$ \\
\hline
\end{tabular}

Quadro 3: Respostas dos estudantes Pré e Pós-aplicação do questionário sobre alimentação dos Quelônios.

Fonte: Dos autores.

Houve uma mudança de $100 \%$ nas respostas com respeito ao conhecimento prévio do tema reprodução. Apesar de termos observado dificuldades, os estudantes descreveram a reprodução antes e depois da visita ao Bosque da ciência. Os alunos tinham bom conhecimento sobre os locais de desova e usavam conceitos científicos em suas respostas (Quadro 4). É interessante ressaltar que um estudante (E10) descreveu que as Tartarugasda-Amazônia tomam sol e desovam em grupo. Os estudantes também descreveram que as tartarugas depositam seus ovos em ninhos e se referiram à cópula (palavra usada no jargão científico) entre o macho e a fêmea.

\begin{tabular}{|l|l|l|}
\hline Aluno & Como eles se reproduzem (nascem)? \\
\hline & Pré & Pós \\
\hline E10 & Não sei & Na praia, quando uma vai, todas vai \\
\hline E51 & Não sei & $\begin{array}{l}\text { As mães, elas cavam um buraco e coloca o ovo, } \\
\text { ai eles nascem. }\end{array}$ \\
\hline E81 & $\begin{array}{l}\text { De ovos que as fêmeas chocam } \\
\text { em praia }\end{array}$ & Alguns botam ovos nas praias outros em mato. \\
\hline
\end{tabular}




\begin{tabular}{|l|l|l|}
\hline E100 & Não sei & $\begin{array}{l}\text { O macho e a fêmea eles copulam e a fêmea bota } \\
\text { os ovos. }\end{array}$ \\
\hline
\end{tabular}

Quadro 4: Respostas dos estudantes Pré e Pós-aplicação do questionário sobre reprodução dos Quelônios.

Fonte: Dos autores.

Ressaltamos que inicialmente somente $10 \%$ dos estudantes questionados conseguiram responder satisfatoriamente às diferenças entre machos e fêmeas. É animador registrar que 54\% dos alunos puderam descrever essas diferenças após a visita (quadro 5).

Com respeito ao dimorfismo sexual esta relaciona-se apenas com características físicas e comportamentais que diferenciam um sexo do outro, como o tamanho do corpo, largura da carapaça e coloração da cabeça. Sabendo que existem essas diferenças, pudemos analisar respostas como do E55 que lembrou que a "barriga" (plastrão) dos machos são para dentro, o que ocorre normalmente nas espécies terrestres como os jabutis. O E17 lembrou do comprimento da cauda, e que na maioria das espécies os machos possuem caudas mais compridas. Já os estudantes E6 e E98 distinguiram os sexos por que predomina nos machos as manhas amarelas na cabeça, diferente da fêmea que perdem os sinais de manchas amarelas quando atinge a maturidade possuindo uma coloração marrom ferrugem.

\begin{tabular}{|l|l|l|}
\hline Aluno & \multicolumn{2}{|l|}{ Você sabe qual a diferença do macho e da fêmea? } \\
\hline & Pré-questionário & Pós-questionário \\
\hline E17 & Não & O macho que o rabo maior e a fêmea menor \\
\hline E55 & Não sei & O macho tem a barriga para dentro e a fêmea não \\
\hline E6 & Não & O macho tem pinta amarela e a fêmea não \\
\hline E98 & $\begin{array}{l}\text { O macho e grande e } \\
\text { a fêmea é menor }\end{array}$ & $\begin{array}{l}\text { O macho tem pintinhas amarelas e a fêmea pescoço marrom isso } \\
\text { só com os tracajás }\end{array}$ \\
\hline
\end{tabular}

Quadro 5: Respostas dos estudantes Pré e Pós-aplicação do questionário sobre dimorfismo sexual dos Quelônios.

Fonte: Dos autores.

Ressaltamos o registro de um elevado número de espécies mencionadas por parte dos estudantes. Enquanto que na pesquisa prévia com os alunos, $41 \%$ não sabiam citar nenhuma espécie, na pós, todos acertaram no mínimo uma questão. Podemos dizer que $83 \%$ dos estudantes acertaram mais de uma espécie. É interessante observar a clareza ao citar o nome correto das espécies, que a apesar de serem nomes populares, não são comuns. Um estudante se destacou (E99), pois o descreveu como "cagado de possas de florestas" que foi uma das espécies menos questionadas e pouco conhecida na Amazônia, 
porém ele a descreveu com propriedade, apesar dos erros ortográficos, foi o único que citou esta espécie (Quadro 6).

\begin{tabular}{|l|l|l|}
\hline Aluno & Que tipos de tartaruga você conhece? \\
\hline & Pré & Pós \\
\hline E40 & Não conheço & $\begin{array}{l}\text { Jabutis, tracajás, mata-matá, cabeçudo e tartaruga da } \\
\text { Amazônia }\end{array}$ \\
\hline E24 & Bom, eu já vi, só não sei o tipo & $\begin{array}{l}\text { Tracajá, tartaruga da Amâzonia, cabeçudo, mata-matá, } \\
\text { jabuti e etc. }\end{array}$ \\
\hline E91 & Nenhuma & $\begin{array}{l}\text { Tracaja, tartaruga da Amazônia, mata-mata, irapuca, } \\
\text { cabeçudo, pitiú. }\end{array}$ \\
\hline E99 & Tartaruga marinha & $\begin{array}{l}\text { Mata-mata, tracajá, irapuca, cagado de possas de } \\
\text { florestas, cabeçudo, perema e tartaruga da Amazônia. }\end{array}$ \\
\hline
\end{tabular}

Quadro 6: Respostas dos estudantes antes e após aplicação do questionário sobre as diversas espécies de Quelônios.

Fonte: Dos autores.

\subsection{Longevidade das tartarugas}

Para Clóvis Bujes (s.d.), Coordenador do Projeto Chelonia-RS, do Departamento de Zoologia do Instituto de Biociências da Universidade Federal do Rio Grande do Sul (UFRGS) "O tempo de vida de um quelônio é muito controverso, e vai depender da espécie e do ambiente onde ela ocorre". Entre o pré e pós-questionário percebe-se uma variação nas respostas sobre a idade das tartarugas. As pesquisas científicas ainda são escassas quanto a esse tema. A assimilação do conhecimento na visita sobre as idades das espécies não foi satisfeita devido ao pouco conhecimento que se tem sobre esse assunto. Um baixo porcentual (4\%) dos estudantes não sabia sobre esta questão, 19\% das respostas variaram entre 20 a 80 anos, o maior percentual (60\%) cito de 90 a 130 anos, enquanto que $10 \%$ dos estudantes citaram a idade entre 140 a 150 anos e $7 \%$ disseram que a idade varia de espécie para espécie.

\section{Considerações finais}

O Bosque da Ciência, se inclui na categoria de espaço não formal institucionalizado que deve ser utilizado para trabalhar a Alfabetização Científica. Nele encontramos ambientes com condições para se trabalhar a biologia e ecologia dos quelônios amazônicos e desta maneira alfabetizar os estudantes em temáticas relacionadas com a realidade amazônica.

No Bosque da Ciência o espaço que apresenta melhor infra-estrutura para trabalhar a Alfabetização Científica usando os quelônios amazônicos foi o CEQUA. Nele 
é possível utilizar recursos de multimídia como vídeos das Tartarugas-da-Amazônia que atraíram bem a atenção dos participantes. $\mathrm{O}$ ambiente apresenta riqueza de espécies e possibilidade de contato dos animais com os estudantes.

Hoje mais do que nunca devemos despertar os cientistas que cada educando possui, e incentivá-los para um crescimento intelectual com possibilidades para novas descobertas. Nesse sentido os espaços não formais apresentam condições para propiciar a curiosidade dos estudantes sobre assuntos que podem passar despercebidos em sala de aula.

Podemos concluir que os espaços não formais são fontes preciosas para as discursões científicas, onde o processo de alfabetização científica deve ser bem trabalhado. As atividades desenvolvidas serviram para preparar os estudantes como cidadãos participantes do meio científico, onde a ciência se tornou parte de sua realidade.

\section{Referências}

ANDRADE, P. C. M. Criação e manejo de quelônios no Amazonas. Manaus: Ibama, ProVárzea, 2007.

BUJES, C. Coordenador do Projeto Chelonia-RS, do Departamento de Zoologia do Instituto de Biociências da Universidade Federal do Rio Grande do Sul (UFRGS). Longevidade dos quelônios. [S.1.: s.d.]. Disponível em: <http://noticias.terra.com.br/educacao/vocesabia/interna>. Acesso em: 14 jun. 2017.

CASCAIS, M. G. A.; FACHÍN-TERÁN, A. Educação formal, informal e não formal na educação em ciências. Ciência em tela, Rio de Janeiro, v.7, n.2, p. 1-8, 2014.

CASCAIS, M. G. A.; FACHÍN-TERÁN, A. Os espaços educativos e a Alfabetização

Científica no ensino fundamental. Manaus: Editora e Gráfica Moderna, 2015.

CHASSOT, A. Alfabetização Científica: questões e desafio para a educação. 5. ed. Revisada. Ijuí: Editora Unijuí, 2010.

CUNHA, A. M. O. Ensino de Ecologia em espaços não formais. In: CONGRESSO LATINO AMERICANO DE ECOLOGIA, 3.; CONGRESSO DE ECOLOGIA DO BRASIL, 9., 2009, São Lorenço. Anais... São Lourenço, MG: SEB, 2009.

ERICKSON, F. Qualitative methods in research on teaching. In: WITTROCK, M. C. (Ed.). Hanbook of research on teaching. 3 ed. New York: Macmillan Publishing Co, 1986.

GOHN, M. G. Educação não formal, participação da sociedade não civil e estruturas colegiadas nas escolas. Ensaio: avaliação e políticas públicas em educação, Rio de Janeiro, v. 14, n. 50, p. 27-38, 2006.

JACOBUCCI, D.F.C. Contribuições dos espaços não-formais de educação para a formação da Cultura Científica. Em extensão, Uberlândia, v. 7, p. 55-66, 2008. 
LORENZETTI, L.; DELIZOICOV, D. Alfabetização Científica no contexto das séries iniciais. Ensaio - Pesquisa em Educação em Ciências, Belo Horizonte, v.3, n.1, p. 45-61, jun. 2001. Disponível em: <www.scielo.br/pdf/epec/v3n1/1983-2117-epec-3-01-00045.pdf〉. Acesso em: 14 jun. 2017.

MACIEL, H. M.; FACHÍN-TERÁN, A. O Potencial Pedagógico dos Espaços Não Formais da Cidade de Manaus. Curitiba, PR: CRV, 2014.

MOREIRA, M. A. Metodologias de Pesquisa em Ensino. São Paulo: Editora Livraria da Física, 2011.

ROCHA, S. C. B; FACHÍN-TERÁN, A. O uso de espaços não-formais como estratégia para o Ensino de Ciências. Manaus: UEA Edições, 2010.

VOGT, R. C. Tartarugas da Amazônia. Instituto Nacional de Pesquisa da Amazônia; Amazon Conservation Association. Impresso em Lima, Peru, 2008.

Recebido em: 05 de fevereiro de 2018.

Aceito em: 06 de abril de 2018. 
O que são tartarugas?

APÊEDICE: Conceitos padrões para as temáticas abordadas

Tartarugas são répteis, participante da ordem dos quelônios. Conhecidos como bicho de casco. Suas espécies tem uma variedade de tamanhos, indo de $20 \mathrm{~cm}$ (pequena) até $70 \mathrm{~cm}$ (grande). Possuem uma carapaça (casco) sua parte superior e a parte ventral chamamos de plastrão.

\section{Morfologia das tartarugas}

Vogt (2008) caracteriza as diversas espécies de quelônios da Amazônia:

Tartarugas-da-Amazônia (Podocnemis expansa) possuem casco (carapaça) largo, achatado e liso, de coloração entre cinza e preto.

Tracajá (Podocnemis unifilis), possuem seu casco em forma de cúpula, apresenta em sua cabeça manchas amarelas.

Irapuca (Podocnemis erythrocephala) possui um padrão de cor avermelhar ou laranja-avermelhado em sua cabeça, com carapaça marrom-escura a preta.

Pitiú (Podocnemis sextuberculata) apresenta seis tubérculos na sua região ventral conhecida como plastrão quando filhotes até juvenis, a carapaça é marcada por sua quilha protuberante na paste posterior das vértebras.

Cabeçudo (Peltocephalus dumerilianus) é uma tartaruga com a cabeça bem avantajada, com carapaça cor de oliva é lisa, com quilha baixa e o plastrão é amarelado.

Mata-matá (Chelus fimbriata) com sua cabeça plana e triangular, olhos pequenos, longo focinho em forma de tubo, pescoço longo $\mathrm{cm}$ numerosas fimbrias. Seu casco semelhante a folhas com protuberâncias. Cor marrom ferrugem com marcas pretas espalhadas na carapaça e seu plastrão é amarelo claro.

Jabuti machado: (Platemys platycephala) é uma pequena espécie. Com carapaça plana e uma parte funda no meio das duas quilhas que são formadas. É de cor marrom-chocolate com faixa lateral variando de marrom-escuro a preto.

Cágado vermelho (Rhinemys rufipes) membros e cabeça de coloração avermelhada, com faixa central e lateral preta. A carapaça é marrom e o plastrão é amarelado.

Cágado de barbicha (Phrynops geoffroanus) com coloração laranja avermelhado com pontos pretos e manchas na parte inferior nos juvenis, quando adultos a coloração da carapaça achatada e lisa desbota para amarelo esverdeado.

Cágado de poças de florestas (Mesoclemmys gibba) com carapaça larga e achatada de coloração marrom, com uma quilha rasa. O plastrão é marrom-escuro.

Muçuã (Kinosternon scorpioides) sua carapaça possui três quilhas. O plastrão é longo e com dobradiças. As marcas da cabeça são vermelhas.

Perema (Rhinoclemmys punctularia) com sua carapaça bem curvada de coloração marrom-escuro a preta, o plastrão é preto no centro e com amarelo pálido nas bordas. Os membros são amarelos alaranjados.

Jabuti Piranga (Chelonoidis carbonarius) a carapaça é de cor preta marcada com amarelo ou vermelhoalaranjado no centro dos escudos. Algumas escamas da cabeça, assim como as da pata são vermelhas ou laranjas, puxando para o amarelo. O plastrão é rígido com a coloração amarela com marcas centrais escuras.

Jabuti Amarelo (Chelonoidis denticulatus) é maior que o Jabuti piranga. A carapaça de cor marrom-claro e os centros dos escudos costais marrom-amarelado-claro, com linhas retas. Escamas da cabeça assim como as dos membros são de cor amarelas-pálidas. O plastrão amarelo-amarronzado.

\section{Alimentação}

A Amazônia conta com espécies de tartarugas herbívoras (se alimentam de folhas, talhos e sementes), carnívoras (se alimentam de presas de origem animal) e onívoras (se alimentam tanto de vegetais quanto de carne).

\section{Habitat}

As tartarugas da Amazônia são classificadas em aquáticas, semiaquáticas e terrestres.

\section{Reprodução}

As tartarugas se reproduzem através da cópula (relação sexual ou coito), de um macho e uma fêmea. Onde o macho introduz seu órgão genital na fêmea liberando seus espermatozóides para fecundar os óvulos, formando assim no processo os ovos que serão depositados nas praias, barrancos, ou folhagens dependendo da espécie.

\section{Dimorfismo sexual}

O dimorfismo se apresenta da seguinte maneira: O tamanho da cauda do macho é maior que a da fêmea. A parte ventral (plastrão) nos machos comumente é mais côncava para o encaixe na fêmea. No caso do Tracajá, a femea perde a pintas amarelas na cabeça quando adultas. Na Tartaruga-da-Amazônia a fêmea é maior que o macho, diferente da fêmea do cabeçudo que é menor. 